\title{
Impact of seizure control on headache characteristics in epileptic patients
}

\author{
Mohamed A. Sayed 1, Hazem K. Ibrahim 1, Mohamed N. Thabit 1, \\ Alaaeldinsedky 1, MostafaAbdelmomen 1 \\ 1 Department of Neurology, Sohag University Hospital, Sohag University, Sohag, \\ Egypt.
}

\begin{abstract} poorly under-stood. epileptic patients. interictal EEG to all patients. antiepileptics. decrease its frequency .

\section{Introduction}

Epilepsy is one of the most prevalent non communicable neurologic conditions and an important cause of disability and mortality. It is estimated to affect almost 70 million people worldwide. The prevalence of epilepsy in low- and middle-income countries is about twice that of high-income countries . (1). Headache and epilepsy are two relatively common neurological disorders and their relationship is still a matter of debate. Epilepsy and primary headache disorders affect individuals of all ages worldwide. Several studies have been performed to asses if there is a relationship between the two conditions, in order to verify the existence of a causal association or if the two disorders can occur in the same individual by chance ( 2 ). Headache is one of the comorbidities that may add to the burden of epilepsy. Headache may be temporally linked to seizures in different ways (3).In clinical practice,
\end{abstract}

Background: Epilepsy and headache are the two most common neurologic disorders affecting individuals of all ages worldwide. The relation between headache and epilepsy is complicated, and the comorbidity of headache and epilepsy is still

Aim of the work: Study of headache characteristics in controlled and uncontrolled

Methods:We evaluated headaches in 100 consecutive patients with epilepsy attending outpatient clinic and epilepsy clinic at Sohag university hospital and performed

Results:. In our study we found that the occurrence of headaches being linked to longer duration of epilepsy, high frequency of seizures and use of polytherapy of

Conclusion:Control of seizures in epileptic patients help in controlling headaches and

patients with epilepsy not infrequently complains of headaches, but they primarily seek treatment of their seizures. Clinicians often fail to explicitly ask the patients about seizure-associated headache, although headache treatment might offer a therapeutic option.( 4). Patients with epilepsy have more disabling headaches and a high prevalence of medication overuse headache (5). According to its temporal relationship with epileptic seizures, headache can be classified as inter-ictal (inter-IH) or peri-ictal (peri-IH). Inter-IH is not temporally related to seizures, whereas peri-IH manifests in their time frame (pre-ictally, ictally, post-ictally) (2).

Patients and Methods:The study was across-sectional study carried on 100 consecutive patients with epilepsy attending outpatient clinic and epilepsy clinic at Sohag university hospital in the period from September 2016 to December 2017. The inclusion criteria 
SOHAG MEDICAL JOURNAL

Vol. 23No. 2 Apr 2019

were patients had a definite diagnosis of epilepsy for one year. Patients with mental retardation, learning disabilities, behavioral disorders or other evident abnormalities that could compromise cooperation and the ability to respond the questionnaires have been excluded. Secondary (symptomatic) epilepsy had be excluded. Montreal cognitive assessment (MOCA) below 26 had been excluded. We obtained a written informed consent from the participants after receiving a complete description of the study. All subjects included in the study were subjected to the following:

1) complete physical and neurologic examination.2) EEG : All spontaneous EEGs were recorded in a resting awake condition with eyes closed The EEG data were acquired by a computerbased system ( Nihon KohdenNeurofax , SN:00429 ) from 16 electrode locations according to the 10/20 system) : Fp1, Fp2, F7, F3, F4, F8, T3, C3, C4, T4, T5, P3, P4, T6, O1, and $\mathrm{O} 2$ and interpretation done with bipolar montage.3) brain imaging (CT brain or MRI brain) to exclude organic causes. 4) routine laboratory investigations.5) assessment of epilepsy was done by direct interview and questionnaire with the patient including the following information :type of epilepsy according to the criteria of The International League Against Epilepsy (ILAE) 2010 ,frequency was divided to four grades ( $<1$ /year , $\geq 1 /$ year, $<1 /$ month , $\geq 1 /$ month, $<1 /$ week , $\geq 1 /$ week) (6) , ,medications, predisposing factors, family history of headache and
Impact of seizure control on headache

Mostafa Abdelmomen.et al

epilepsy, hospital admission , investigations, history of febrile convulsions, use of analgesic and type of analgesic.6) A questionnaire to determine type of headache was done according to the InternationalHeadache-Classification-III-ICHD-III2013-Beta.According to the temporal relationship with seizures (i) Peri-IH is divided into pre-ictal headache (preIH), ictal and post-ictal headache (post$\mathrm{IH})$. Pre-IH was defined as appearing within $24 \mathrm{~h}$ before the seizure. Ictal headache was present exclusively during the seizure. Post-IH was defined according to the ICHD-II as a headache which develops within $3 \mathrm{~h}$ following a partial or generalized seizure and resolves within $72 \mathrm{~h}$ after the seizure. (ii) Inter-IH is all headaches that manifested within a time period of the epileptic disease and whose attacks were not temporally related to an epileptic seizure.7) severity of headache was determined by the patients on a visual analogue scale and divided into mild, moderate and severe.

\section{Statistical analysis:}

Data was analyzed using STATA intercooled version 12.1. Quantitative data was represented as mean, standard deviation, median and range. Data was analyzed using student t-test to compare means of two. When the data was not normally Mann-Whitney test was used. Qualitative data was presented as number and percentage and compared using either Chi square test or fisher exact test. Graphs were produced by using Excel or STATA program. $P$ value was considered significant if it was less than 0.05 .

\section{Results}

Study population : The study was carried on 100 epileptic patients . The mean \pm SD for patient's age was $24.7 \pm 8.20$. Female patients were 59 represented $(59.00 \%)$ while male patients were 41 represented $(41.00 \%)$.

Epilepsy related data : Focal seizures occurred in 74 patients $(74 \%)$, generalized occur in 25 patients $(25 \%)$ and unclassified seizures in one patient $(1 \%)$. The mean \pm 
SD for patient's age at onset of epilepsy is $16.26 \pm 8.88$. The mean \pm SD for patient's duration of epilepsy is $8.39 \pm 5.33$.According to the number of antiepileptic drugs used for epilepsy treatment , 3 patients (3\%) use no antiepileptic drugs , 50 patients (50\%) use monotherapy for treatment and 47 patients (47\%) use polytherapy for treatment .The frequency of seizures in our patients was as the following :There were 19 patients $(19 \%)$ had $(<1$ seizure per year), 17 patients $(17 \%)$ had $(\geq 1$ seizure per year,$<1$ seizure per month) , 44 patients $(44 \%)$ had $(\geq 1$ seizure per month,$<$ 1 seizure per week) and 20 patients $(20 \%)$ had ( $\geq 1$ seizure per week). According to the use valproate or topiramte for epilepsy treatment , 43 patients $(43 \%)$ use valproate or topiramte.According to previous history of febrile convulsions , 89 patients (89\%) had no previous history of febrile convulsions and only 11 patients (11\%) had previous history of febrile convulsions .According to family history of epilepsy , 82 patients $(82 \%)$ had no family history of epilepsy while 18 patients $(18 \%)$ had positive family history of epilepsy. According to family history of chronic headache which had the criteria of migraine headache and its subtype , 88 patients $(88 \%)$ had no family history of chronic headache and 12 patients (12\%) had positive family history of chronic headache .Inter ictal EEG findings in patients were as follow : Normal in 41 patients (41\%), 51patients (51\%) had focal epileptic EEG including 27 patients $(27$ $\%)$ had left focal and 24 patients $(24 \%)$ had right focal while generalized epileptic EEG in 8 patients $(8 \%)$.

Comparison between headache group and non-headache group:

Population characteristics and intergroup differences analysis results regarding headache existence are shown in (Table 1). There were significant intergroup differences in longer duration of epilepsy, high frequency of seizures, and EEG finding.

Antiepileptic drugs : Patients with headaches tended to use a higher number of antiepileptic drugs (57.69\%) than those without headaches $(9.09 \%)(\mathrm{p}=<0.0001)$

\begin{tabular}{|c|c|c|c|}
\hline Variables & $\begin{array}{l}\text { No headache } \\
\mathrm{N}=22\end{array}$ & $\begin{array}{l}\text { Headache } \\
\mathrm{N}=78\end{array}$ & $P$ value \\
\hline $\begin{array}{l}\text { Epilepsy duration } \\
\text { Mean } \pm \text { SD }\end{array}$ & $3.41 \pm 2.41$ & $9.79 \pm 5.09$ & $<0.0001$ \\
\hline $\begin{array}{l}\text { Type of therapy } \\
\text { No therapy } \\
\text { Monotherapy } \\
\text { Poly therapy }\end{array}$ & $\begin{array}{l}0 \\
20(90.91 \%) \\
2(9.09 \%)\end{array}$ & $\begin{array}{l}3(3.85 \%) \\
30(38.46 \%) \\
45(57.69 \%)\end{array}$ & $<0.0001$ \\
\hline $\begin{array}{l}\text { Frequency of } \\
\text { epilepsy } \\
<1 / \text { year } \\
\geq 1 / \text { year, }< \\
1 / \text { month } \\
\geq 1 / \text { month, }< \\
1 / \text { week } \\
\geq 1 / \text { week }\end{array}$ & $\begin{array}{l}9(40.91 \%) \\
8(36.36 \%) \\
3(13.64 \%) \\
2(9.09 \%)\end{array}$ & $\begin{array}{l}10(12.82 \%) \\
9(11.54 \%) \\
41(52.56 \%) \\
18(23.08 \%)\end{array}$ & $<0.0001$ \\
\hline $\begin{array}{l}\text { History of febrile } \\
\text { convulsions } \\
\text { No } \\
\text { Yes }\end{array}$ & $\begin{array}{l}21(95.45 \%) \\
1(4.55 \%)\end{array}$ & $\begin{array}{l}68(87.18 \%) \\
10(12.82 \%)\end{array}$ & 0.45 \\
\hline $\begin{array}{l}\text { EEG finding } \\
\text { Normal } \\
\text { Generalized } \\
\text { Focal } \\
\end{array}$ & $\begin{array}{l}18(81.82 \%) \\
1(4.55 \%) \\
3(13.64 \%) \\
\end{array}$ & $\begin{array}{l}23(29.49 \%) \\
7(8.97 \%) \\
48(61.54 \%)\end{array}$ & $<0.0001$ \\
\hline
\end{tabular}

Table (1)intergroup differences analysis results regarding headache existence 
SOHAG MEDICAL JOURNAL

Vol. 23No. 2 Apr 2019

\section{Discussion}

A large proportion of patients with epilepsy in our study (78\%) have headaches, which is similar to the frequency of $(83.2 \%)$ reported by (7). In contrast to our result some studies reported a lower frequency of headache in epileptic patients as $(22 \%)$ by (8) and (34\%) by (9) and this can explained by inclusion of patients with less refractory epilepsy (8) and are possibly due to variations in the characteristics of recruited patients with epilepsy including age, newly diagnosed patients or patients referred to tertiary centers, study design, and/or diagnostic criteria (10).

Also we found that there was along mean duration of epilepsy in patients with headaches $(9.79 \pm 5.09)$ compared to those without $(3.41 \pm 2.41)$ and this result is in agreement with (18) and this could be explained that headache is more common with intractable epilepsy with long duration and the interrelationship between two disorders. On the other hand some studies reported no statistically significant differences in mean duration of epilepsy between patients with headaches compared to those without (Heo et al., 2010).We found that there was a higher frequency of seizures in patients with headaches $(75.5 \%)$ compared to those without $(22.6 \%)$ and this is reported by other studies $(3 ; 9 ; 11 ; 2 ; 6)$ and this could be explained that seizures act as a trigger for headache occurrence and recurrence of seizures could cause CSD in patients that could then increase the frequency of headaches. But few other studies report no relation between headache occurrence and frequency of seizures $(13 ; 10)$. We also found that Patients

with headaches tended to use a polytherapy of antiepileptic drugs $(57.69 \%)$ than those without headaches $(9.09 \%)$ and this result is in agreement with $(3 ; 19 ; 20 ; 13 ; 2)$

and this suggested that headaches could befrequent in refractory patients using polytherapies of antiepileptic drugs and also in chronic active or intractable forms of epilepsy.

Our results also showed that EEG abnormalities are significantly occur in patients with headache $(70.5 \%)$ compared to those without (18.2\%) and by the type of abnormality focal changes are the commonest in patients with headache $(61.54 \%)$ compared to those without (13.64\%) and the same findings reported by $(15 ; 22)$ and those results suggest the triggering factor of epilepsy for headache and the common pathophysiological mechanisms $(15 ; 25 ; 22)$ and the predominance of focal changes in EEG are due to predominance of headache in focal onset seizures and these findings suggest that an epileptic focus that activates the trigemino-vascular system might remain purely autonomic, without ictal neuronal activation of non-autonomic cortical areas. (9).

Study limitations :Our study has some limitations that need to be addressed. First, our interview was dependent on patients' memory of headaches.Secondly , Findings reported here are based on a sample size of 100 participants.

\section{Conclusion:}

Our study showed that patients with epilepsy frequently experience headaches.we found that the occurrence of headaches being linked tolonger duration of epilepsy, high frequency of seizures and use of polytherapy of antiepileptics. Also there is association between presence of headache and EEG abnormalities mostly with focal ones.

\section{References}

1. Ngugi, A. K. et al. (2011) 'Incidence of epilepsy: A systematic review and 
SOHAG MEDICAL JOURNAL

Vol. 23No. 2 Apr 2019

meta-analysis', Neurology, pp. 1005-

1012.

doi:

10.1212/WNL.0b013e31822cfc90.

2. Mainieri, G. et al. (2015) 'Headache in epilepsy: prevalence and clinical features', Journal of Headache and Pain, 16(1). doi: 10.1186/s10194-0150556-y.

3. Syvertsen, M. et al. (2007) 'Headaches add to the burden of epilepsy', Journal of Headache and Pain, 8(4), pp. 224230. doi: 10.1007/s10194-007-0398-3.

4. Förderreuther, S., Henkel, A., Noachtar, S., \&Straube, A. (2002). Headache associated with epileptic seizures: epidemiology and clinical characteristics. Headache: the Journal of Head and Face Pain, 42(7), 649655.

5. Kingston, W. S. and Schwedt, T. J. (2017) 'The Relationship Between Headaches with Epileptic and Nonepileptic Seizures: a Narrative Review', Current Pain and Headache Reports. doi: 10.1007/s11916-0170617-9.

6. Çilliler, A. E., Güven, H. and Çomoğlu, S. S. (2017) 'Epilepsy and headaches: Further evidence of a link', Epilepsy and Behavior, 70, pp. 161165.

doi: 10.1016/j.yebeh.2017.03.009.

7. Mameniškienė, R., Karmonaite, I. and Zagorskis, R. (2016) 'The burden of headache in people with epilepsy', Seizure, 41, pp. 120-126. doi: 10.1016/j.seizure.2016.07.018.

8. Kwan, P. et al. (2008) 'Headache in patients with epilepsy: a prospective incidence study.',Epilepsia, 49(6), pp. 1099-102. doi: 10.1111/j.15281167.2008.01574.x.

9. Kanemura, H. et al. (2013) 'Characteristics of headache in children with epilepsy', Seizure, 22(8), pp. 647-650. doi: http://dx.doi.org/10.1016/j.seizure.201 3.04.022.

10. Seo, J.-H. et al. (2016) 'Correlation between headaches and affective symptoms in patients with epilepsy', Epilepsy \& Behavior, 60, pp. 204208.

doi:

10.1016/j.yebeh.2016.03.028.
11. Gameleira, F. T., Ataíde, L. and Raposo, M. C. F. (2013) 'Relations between epileptic seizures and headaches', Seizure, 22(8), pp. 622626.

doi: 10.1016/j.seizure.2013.04.016.

12. Wang, $X$. qing, Lang, S. yang, He, M. wang, et al. (2014) 'High prevalence of headaches in patients with epilepsy', Journal of Headache and Pain, 15(1). doi: 10.1186/1129-237715-70.

13. Wang, $X$. qing, Lang, S. yang, Zhang, X., et al. (2014) 'Comorbidity between headache and epilepsy in a Chinese epileptic center', Epilepsy Research, 108(3), pp. 535-541. doi: 10.1016/j.eplepsyres.2013.12.013.

14. Stovner, L. J. et al. (2007) 'The global burden of headache: A documentation of headache prevalence and disability worldwide', Cephalalgia, pp. 193210. doi: 10.1111/j.14682982.2007.01288.x.

15. Toldo, I. et al. (2010) 'Comorbidity between headache and epilepsy in a pediatric headache center.', The journal of headache and pain, 11(3), pp. 235-240. doi: 10.1007/s10194010-0191-6.

16. Rasmussen, B. K. et al. (1991) 'Epidemiology of headache in a general population-A prevalence study', Journal of Clinical Epidemiology, 44(11), pp. 1147-1157. doi: 10.1016/0895-4356(91)90147-2.

17. Heo, K. et al. (2010) 'Multi-center study on migraine and seizure-related headache in patients with epilepsy', Yonsei Medical Journal, 51(2), pp. 219-224. doi: 10.3349/ymj.2010.51.2.219.

18. Velioğlu, S. K., Boz, C. and Özmenoğlu, M. (2005) 'The impact of migraine on epilepsy: A prospective prognosis study', Cephalalgia, 25(7), pp. 528-535. doi: 10.1111/j.14682982.2005.00912.x.

19. Ekstein, D. and Schachter, S. C. (2010) 'Postictal headache', Epilepsy and Behavior, pp. 151-155. doi: 10.1016/j.yebeh.2010.06.023.

20. Duchaczek, B. et al. (2013) 'Interictal and periictal headache in patients with epilepsy', European Journal of 
Neurology, 20(10), pp. 1360-1366. doi: 10.1111/ene.12049.

21. Wirrell, E. C. and Hamiwka, L. D. (2006) 'Do children with benign rolandic epilepsy have a higher prevalence of migraine than those with other partial epilepsies or nonepilepsy controls?',Epilepsia, 47(10), pp. 1674-1681. doi: 10.1111/j.15281167.2006.00639.x.

22. Verrotti, A., Coppola, G., Spalice, A., et al. (2011) 'Peri-ictal and inter-ictal headache in children and adolescents with idiopathic epilepsy: A multicenter cross-sectional study', Child's Nervous System, 27(9), pp. 1419-1423. doi: 10.1007/s00381-0111428-7.

23. Bolay, H. et al. (2002) 'Intrinsic brain activity triggers trigeminal meningeal afferents in a migraine model', Nature
Medicine, 8(2), pp. 136-142. doi: 10.1038/nm0202-136.

24. Moskowitz, M. A., Bolay, H. and Dalkara, T. (2004) 'Deciphering Migraine Mechanisms: Clues from Familial Hemiplegic Migraine Genotypes', Annals of Neurology, pp. 276-280. doi: 10.1002/ana.20035.

25. Kasteleijn-NolstTrenité, D. G. A. et al. (2010) 'Headache, epilepsy and photosensitivity: How are they connected?', Journal of Headache and Pain, pp. 469-476. doi: 10.1007/s10194-010-0229-9.

26. Caminero, a and Manso-Calderón, $R$. (2014) 'Links between headaches and epilepsy: current knowledge and terminology.', Neurología (Barcelona, Spain), 29(8), pp. 453-63. doi: 10.1016/j.nrl.2011.10.016. 